\title{
Viscoelastic behaviour of highly filled polypropylene with solid and liquid Tin microparticles: influence of the stearic acid additive
}

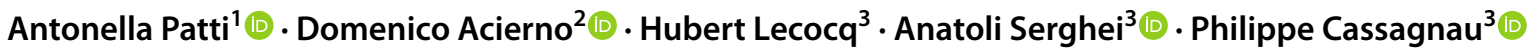

Received: 19 April 2021 / Revised: 27 June 2021 / Accepted: 23 July 2021 / Published online: 12 August 2021

(C) The Author(s) 2021, corrected publication 2021

\begin{abstract}
In this work, highly filled composites made of a commercial polypropylene resin and low melting point Tin particles, up to $50 \mathrm{vol} . \%$ in loadings, have been prepared by melt blending process. The introduction of stearic acid (SA), a common dispersant, was investigated in compositions. The developed systems were characterized in terms of dynamic rheological testing. Final results confirmed a reduction of linear viscoelastic domain, by increasing filler loadings, with an effect more emphasized in the presence of SA. Contrary to literature studies, at equal filler content (50\%), both moduli resulted to be superior for formulations containing the dispersing agent. A further rheological characterization continued on systems at 30 vol.\% of particle loadings for highlighting differences depending on the SA addition. Specific tests were also performed at temperatures above the melting of Tin particles. Finally, optical microscopic analyses were carried out for gaining insight on sample microstructure, in controlled conditions of temperature and shear rate.
\end{abstract}

Keywords Polypropylene $\cdot$ Stearic acid $\cdot$ Highly filled (HF) composites $\cdot$ Rheological characterization

\section{Introduction}

Highly filled composites (HF) are a class of polymer-based system with a solid content greater than $40 \%$ by volume. The processability of HF materials is a complex issue at particle loadings close to the maximum packing fraction. It

Antonella Patti

antonella.patti@unict.it

Domenico Acierno

acierno@crdctecnologie.it

Hubert Lecocq

hubert.lecocq@univ-lyon1.fr

Anatoli Serghei

anatoli.serghei@univ-lyon1.fr

Philippe Cassagnau

philippe.cassagnau@univ-lyon1.fr

1 Department of Civil Engineering and Architecture, University of Catania, Viale Andrea Doria 6, 95125 Catania, Italy

2 CRdC Nuove Tecnologie Per Le Attività Produttive Scarl, Via Nuova Agnano 11, 80125 Naples, Italy

3 Ingénierie Des Matériaux Polymères, CNRS, UMR 5223, Univ-Lyon, Université Claude Bernard Lyon 1, 15 Bd Latarjet, 69622 Villeurbanne Cedex, France can be aided by a useful combination of parameters such as filler shape, orientation, size distribution, and phase interactions (matrix/filler, filler/filler). Such a high level of solid particulate within the matrix can be critical for a variety of applications (Rueda et al. 2017a). First and foremost, it has the potential to be extremely beneficial in terms of heat management and thermal conduction (Hussain et al. 2017). The advancement of performance (speed, efficiency, and reliability) in developing fast computers, more efficient electronic devices, three-dimensional chips, and flexible electronics is limited by the need to ensure effective cooling of devices (Moore and Shi 2014). For these applications, the thermal conductivity of applied materials should be superior of $7 \mathrm{~W} /$ $(\mathrm{m} \mathrm{K})$, as opposed to typical polymer values of 0.1 to $0.5 \mathrm{~W} /$ $(\mathrm{m} \mathrm{K})$. As a result, systems capable of ensuring an efficient heat exchange mechanism by encouraging the release of produced energy are required. To meet these requirements, high loadings of inorganic conductive fillers should be incorporated into polymer resins: the greater the contact between particles, the greater the heat transport (Drozdov and deClaville Christiansen 2019).

The same factors are deemed important in the case of electrical properties for sensors and electronic devices (solar cells, biosensors, and biofuel cells) (Deshmukh et al. 2016). Polymers are considered electrical insulators due to their 
extremely low concentration of free charge carriers: various attempts have been made to improve electrical conduction in polymer matrices by incorporating electrical conductive particles such as carbon-black particles, carbon fibers, and metallic fillers (Planes et al. 2013).

Furthermore, a high amount of filler in matrices is advantageous even for the mechanical properties of final products. Typically, the properties of composites are determined by the intrinsic properties of the pristine constituents (matrix and filler) as well as the adhesion of two phases. The presence of particles with high percentages of strength and hardness may have reinforcing effects by improving the mechanical strength and stiffness of basic polymers (Kajohnchaiyagual et al. 2014).

Recently, HF composites have been successfully involved in innovative technology of additive manufacturing (AM) (Fallon et al. 2019), specifically Powder Injection Molding (PIM). In the latter case, HF systems are an alternative solution for avoiding structural defects and stress points in sintered parts (Zürcher and Graule 2005). Yet, the presence of particles determines strongly changes in rheological behavior of matrix (Cassagnau and Mélis 2003), by causing a remarkable increase of mixture viscosity (Cassagnau 2008) and melt instabilities during flow (Palza et al. 2010). The composite material used in this process should have adequate stiffness, conductivity, flexibility and flowability. Good viscosity, strength, and modulus are critical characteristics for promoting flow along the conduit, melting, and material extrusion. In fact, when the system has high viscosity and low stiffness, twisting phenomena can complicate or even make the process impossible (Nikzad et al. 2011). Another critical aspect of the PIM process is the uniform distribution of metal or ceramic particles within the molten binder. Feedstock preparation is scrutinized to avoid filler aggregation and ensure reduced component segregation during shaping. This also limits isotropic shrinkage after debinding and/or sintering (Gonzalez-Gutierrez et al. 2018). Additives such as surface modifiers, coupling agents, surfactants and dispersants are decisive in the development of HF formulations. For example, fluorine-containing flow modifiers with low surface energy have been used in magnesium hydroxide (MH)/linear low-density polyethylene (LLDPE) composites for simultaneous improvement of processability and toughness (Cao et al. 2020). The effect of different components, based on titanate and silane coupling agent, silicon oil and silane-grafted high density polyethylene formulations on the mechanical properties of linear low density polyethylene and aluminium hydroxide have been compared by Zhu et al. (2002). Alkyl ammonium surfactant has been added in polyamide 6/clay nanocomposites to increase protective barrier stability against fire (Dasari et al. 2007). Electrosteric (polyacrylic acid), electrostatic (triammonium citrate), and steric dispersant (2-(2-(2 methoxy ethoxy) ethoxy) acetic acid) have been adopted in nano-zirconia suspensions. Water and water-1,2-propanediol mixtures were used as continuous aqueous phases for analyzing related effects on viscosity and elasticity (Renger et al. 2007). The stearic acid (SA) is one of the most common processing aids, used for reducing distortions and flow irregularities (Achilleos et al. 2002), and promoting filler dispersion during compounding (Lazzeri et al. 2005). It is demonstrated that this chemical species, composed of a long hydrocarbon chain (a-polar portion) and a carboxyl group (polar portion), can perform a variety of tasks: it favors lubrication, improves melted phase workability, and/or interacts with surfaces via physical or chemical mechanisms. This results in particle charge modification and formation of layered structures surrounding the surface, which promote steric hindrance, decrease surface energy, and increase the hydrophobic character of treated surfaces. As a result, filler/matrix compatibility is improved, the viscosity is reduced, and filler dispersion is increased (Patti et al. 2021).

In this framework, this study proposes understanding the role of stearic acid in affecting the viscoelastic behaviour of highly filled composites based on commercial polypropylene resin. Tin microparticles with a low melting point are chosen as a filler and added to the neat matrix in amounts up to $50 \%$ vol. On prepared systems, dynamic rheological tests are carried out at temperatures below and above the melting point of the particles. Optical microscopy techniques are used to examine structural dynamic changes in composites as well as particle solid-liquid transition under controlled temperature and shear flow conditions.

\section{Materials and methods}

\section{Materials}

As matrix, a commercial polypropylene grade (PPH7060, homopolymer, melt flow index of $12 \mathrm{~g} / 10 \mathrm{~min}$ at $230^{\circ} \mathrm{C}$ and $2.16 \mathrm{~kg}$ ) was supplied by Total Petrochemicals \& Refining (Bruxelles, Belgique). Stearic acid, used as surface modifier, was provided in form of flakes (purity 95\%) by Sigma Aldrich (Saint Louis, USA). Tin particles (average diameter of $45 \mu \mathrm{m}$ ) were acquired from Goodfellow France.

\section{Sample preparation}

Formulations containing 10, 30, and $50 \mathrm{vol} . / \mathrm{vol} . \%$ of Tin particles were prepared in a batch mixer (Thermoscientific Polylab OS RheoDrive 7 Haake). To avoid overheating and melting of particles during the compounding, temperature of $190{ }^{\circ} \mathrm{C}$ and screw speed of $30 \mathrm{rpm}$ for $10 \mathrm{~min}$ and $50 \mathrm{rpm}$ for $3 \mathrm{~min}$ were fixed. Some compositions were realized by adding stearic acid. An amount of dispersant agent equal 
to 6 and 9 vol./vol.\% was introduced in systems at 30 and 50 vol.\% of microparticles, respectively. Then, compounds were pelletized in a grinder (mod. Pulverisette 19), produced by Frisch (Pittsboro, USA) by using liquid nitrogen. Discshaped specimens were prepared by compression molding using a press (mod. Polystat 200 T), provided by Servitec (Wustermark, Germany), in conditions of temperature of $200{ }^{\circ} \mathrm{C}$ and pressure of $250 \mathrm{bar}$.

\section{Characterization techniques}

The viscoelastic behaviour of prepared composites was investigated using an ARES rheometer (TA Instruments, Delaware, USA). Parallel plates with a diameter of $25 \mathrm{~mm}$ were adopted for neat PP and samples with a filler loading of $10 \%$. In the case of compositions containing 30 and $50 \mathrm{vol} . \%$ Tin, small plates with a diameter of $8 \mathrm{~mm}$ were utilized. Frequency sweep test were conducted at $190{ }^{\circ} \mathrm{C}$ from 100 to $0.1 \mathrm{rad} / \mathrm{s}$ under air atmosphere. To establish linear viscoelastic region (LVE) with a strain independent modulus, preliminary strain sweep tests were carried out at fixed frequency of $10 \mathrm{rad} / \mathrm{s}$ in range of deformation between $10^{-2}$ and $10^{2}$.

At $190{ }^{\circ} \mathrm{C}$ in nitrogen atmosphere, cyclic tests were planned to highlight differences in viscoelastic behaviour for systems containing $30 \%$ in vol. of particles, with or without dispersant agent. Five consequential steps have followed: (1) strain sweep in range of deformation between $10^{-2}$ and $10^{2}$ at $10 \mathrm{rad} / \mathrm{s}$ to identify the LVR. Based on the results of this test, strain value of $0.5 \%$ was chosen to ensure frequencyindependent modulus; (2) frequency sweep was conducted to analyze the viscoelastic response of both materials at constant strain of $0.5 \%$ in the range of 100 to $0.1 \mathrm{rad} / \mathrm{s}$; (3) following the achievement of rheological percolation, time sweep was performed at strain of $0.5 \%$ and $0.4 \mathrm{rad} / \mathrm{s}$. The lower the frequency, the longer it took to form the percolation network and the greater the measurement accuracy. The latter frequency was chosen as a compromise between experiment duration and measurement accuracy; (4) frequency sweep ranging from 100 to $0.1 \mathrm{rad} / \mathrm{s}$ at constant strain of 0.5 , and (5) strain sweep in range of deformation between $10^{-2}$ and $10^{2}$ at $10 \mathrm{rad} / \mathrm{s}$, to observe changes in morphology attributed to the arrangement of percolated structures.

Then, cyclic testing in nitrogen atmosphere on samples containing $30 \mathrm{vol}$. \% of particles with or without SA was carried out to investigate effects of melted particles on rheological parameters of compounds. It was divided into the following stages: (1) time sweep at $220^{\circ} \mathrm{C}$ for $600 \mathrm{~s}$, heating rate of $20^{\circ} \mathrm{C} / \mathrm{min}$ up to $245^{\circ} \mathrm{C}$, time sweep at $245^{\circ} \mathrm{C}$ so to cross the melting point of Tin particles. In this step, the frequency was set at $3.98 \mathrm{rad} / \mathrm{s}$ resulting as an intermediate value for the number of measurements in the range of $0.1-100 \mathrm{rad} / \mathrm{s}$. According to preliminary strain sweep test the strain was set at $0.1 \%$; (2) at $245{ }^{\circ} \mathrm{C}$, the frequency was swept in the range of 100 to $0.1 \mathrm{rad} / \mathrm{s}$, with a strain of $0.1 \%$. The system was then returned to its initial state of melted polymer/solid particles by (3) cooling to $190{ }^{\circ} \mathrm{C}$ (at a rate of $20^{\circ} \mathrm{C} / \mathrm{min}$ ) followed by time sweep at a frequency of $3.98 \mathrm{rad} / \mathrm{s}$ and a strain of $1 \%$; (4) frequency sweep was performed at $190{ }^{\circ} \mathrm{C}$ in range of $100 \mathrm{rad} / \mathrm{s}$ to 0.1 and fixed strain of $1 \%$, to verify morphological changes induced on the system as a result of the melting/solidification of Tin particles.

To monitor sample morphology under various testing conditions, a polarized optical microscope in transmission (mod. Leica DM 2700 M, Wetzlar, Germany) was used. An optical rheology system (mod. Linkam CSS450) supplied by Linkam Scientific Instruments Ltd. (Tadworth Surrey, UK), a white light source, and a lens with a magnification of $\times 50$ were installed in the instrument. Samples were introduced between two discs with a $1 \mathrm{~mm}$ gap. After reaching the reference temperature, a shear rate of $0.1 \mathrm{~s}^{-1}$ was applied. Images were captured by a charge coupled device camera during evolution (Qimaging, Canada). According to rheological testing, the reference temperature for solid particles analysis in polymer-based compounds was $190^{\circ} \mathrm{C}$. The reference temperature for investigations on molten polymer and particles was set at $210^{\circ} \mathrm{C}$.

\section{Rheological testing on solid particles in polymer-based compounds}

In Fig. 1, the dependence of storage modulus (G') by deformation was reported for developed compounds with and without stearic acid. When the strain was increased, the drastic reduction of modulus was usually attributed to the occurrence of three-dimensional networks made of particle aggregates. These structures affected dynamic viscoelasticity of materials due to density and strength by filler interactions (Cassagnau 2003). This phenomenon was found to be strongly related to the particle content of melted polymer: the higher the loading, the greater the amplitude drop. The distance between particles in melted polymer was large at low filler loadings ( $\mathrm{PP}+10 \% \mathrm{Sn}$ samples), resulting in fewer opportunities to form 3D networks. By exhibiting roughly strain-independence, the storage modulus remained in the order of magnitude of $10^{4} \mathrm{~Pa}$. On the other hand, increasing the filler content within the matrix ( $\mathrm{PP}+50 \% \mathrm{Sn}$ samples) reduced the distance between particles/aggregates by promoting the formation of tridimensional structures in polymer suspensions. In this case, by increasing the strain, the storage modulus decreased. A value of around $10^{7} \mathrm{~Pa}$ was measured in correspondence of deformations less than $10^{-1}$ $(\gamma<0.1 \%)$, reaching order of magnitude of $10^{4} \mathrm{~Pa}$ as the deformation percentage approached $10^{2}(\gamma \geq 10 \%)$. This latter behaviour was commonly referred to as $3 \mathrm{D}$ particle arrangement breakage in the range of high deformations due 
Fig. 1 Strain amplitude sweep for all investigated materials. Test performed in air atmosphere at a frequency of $10 \mathrm{rad} / \mathrm{s}$ and temperature of $190{ }^{\circ} \mathrm{C}$

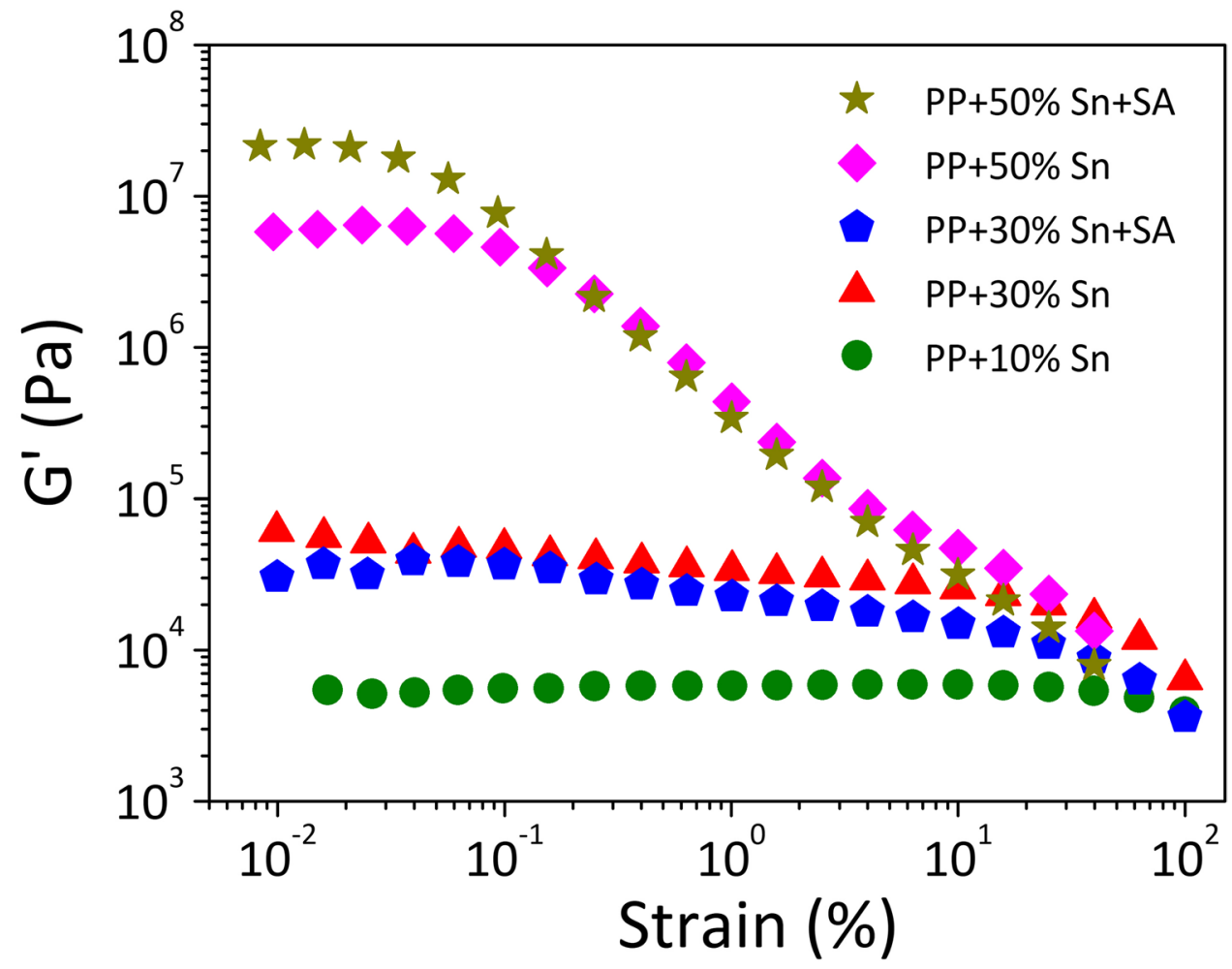

to the dominance of hydrodynamic forces over filler interactions (Cassagnau and Mélis 2003).

When stearic acid was introduced into polymer-based compositions, additional considerations should be made. For composites with filler fractions of 0.3 , SA had no effect on the viscoelastic properties of melted compounds, and $\mathrm{G}^{\prime}$ values were almost identical across the entire range of strain values (from $10^{-2}$ to $10^{2}$ ). As a result, the total curve for $\mathrm{PP}+30 \% \mathrm{Sn}+\mathrm{SA}$ was slightly lower than for $\mathrm{PP}+30 \% \mathrm{Sn}$. When the filler content in composites was equal to $50 \mathrm{vol} . \%$, the effect of the dispersing agent was more evident. $\mathrm{G}^{\prime}$ for $\mathrm{PP}+50 \% \mathrm{Sn}+\mathrm{SA}$ samples was superior to that measured for $\mathrm{PP}+50 \%$ Sn samples at these concentrations, with amplitudes ranging from 0.01 to 0.1 .
To highlight the effects of SA on proposed compositions, a comparison between normalized storage modulus, i.e. the storage modulus $\left(\mathrm{G}^{\prime}\right)$ on storage modulus value at plateau $\left(\mathrm{G}_{0}\right)$, as function of strain, was reported in Fig. 2 for composites without or with SA, (a) at $30 \mathrm{vol} \%$, and (b) at 50 vol. $\%$.

For composites at 30 vol.\%, no differences in LVR were highlighted in the presence or absence of SA, and $\gamma_{c}$ was around 1 . When the filler content was 50 vol. $\%$, the introduction of dispersing agent shortened the limit of linearity: $\gamma_{c}$ was reduced to $0.08 \%$ for $\mathrm{PP}+50 \% \mathrm{Sn}$, and arrived at $0.03 \%$ for $\mathrm{PP}+50 \% \mathrm{Sn}+\mathrm{SA}$. This result was in contrast with screening effects exerted by SA among ferrite particles in polypropylene, verified by Rueda et al. (2017b).
Fig. 2 Normalized values of storage modulus in range of deformations between $10^{-2}$ and $10^{2}$ for samples with or without $\mathrm{SA}$, at 30 vol. $\%$ (a) and 50 vol.\% (b) of Tin particles
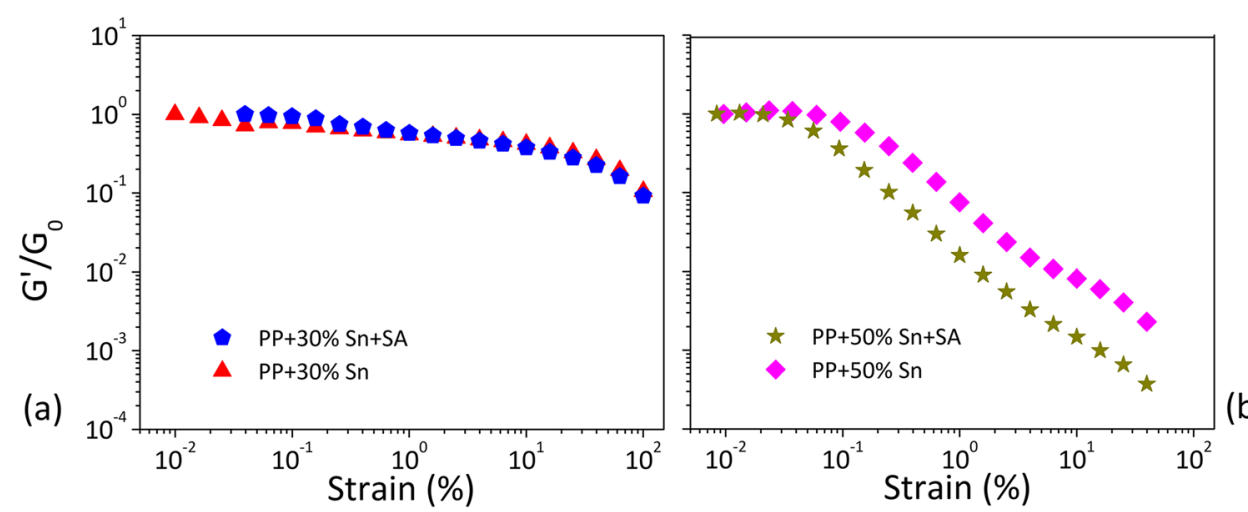
Frequency sweep results were shown for neat and filled PP matrix, up to $50 \%$ of Tin particles, with or without SA, in Fig. 3.

In particular, pure PP exhibited typical entangled polymer behavior, with a terminal zone clearly visible at frequencies closer to $0.1 \mathrm{rad} / \mathrm{s}$ ( $\operatorname{slop} \sim 1.4$ ).

Changes in the viscoelastic response of PP polymer have been determined by the incorporation of micro-particles in matrix, depending on the content. By increasing the filler loading in neat resin (30 vol.\%), an increase in storage modulus was observed, as well as a loss in terminal behavior replaced by a plateau typical of interconnected structures. The storage modulus $\left(\mathrm{G}^{\prime}\right)$ was slightly higher than that of the matrix, with a characteristic trend of liquid-like behaviour, and the terminal slope $(\sim 1)$ was lower in comparison to the PP ( 1.4).

By comparing samples with 30 vol.\% Tin particles with (blue pentagons points) or without SA (red triangles points), the $G$ ' values were very close, indicating that fatty species had no significant effect on tested features.

Then, a drastic change of dynamic response of compounds was attested for filler content of 50 vol.\%. At this concentration, the storage modulus of samples incorporating SA exceeded that recorded for compounds without additive. The value remained in order of magnitude of $10^{6}$ and $10^{7}$ for $\mathrm{PP}+50 \% \mathrm{Sn}$ and $\mathrm{PP}+50 \% \mathrm{Sn}+\mathrm{SA}$, respectively. However, for both $\mathrm{PP}+50 \% \mathrm{Sn}$ and $\mathrm{PP}+50 \% \mathrm{Sn}+\mathrm{SA}$ samples, the $\mathrm{G}^{\prime}$ trend reached an almost constant value across the entire frequency range, ending at low frequencies with an equilibrium plateau and vanishing slope $\left(G^{\prime} \propto \omega^{0}\right)$. This condition was representative of solid-like behaviour achieved by the formation of three-dimensional filler networks and the crossing of critical concentrations, also known as percolation

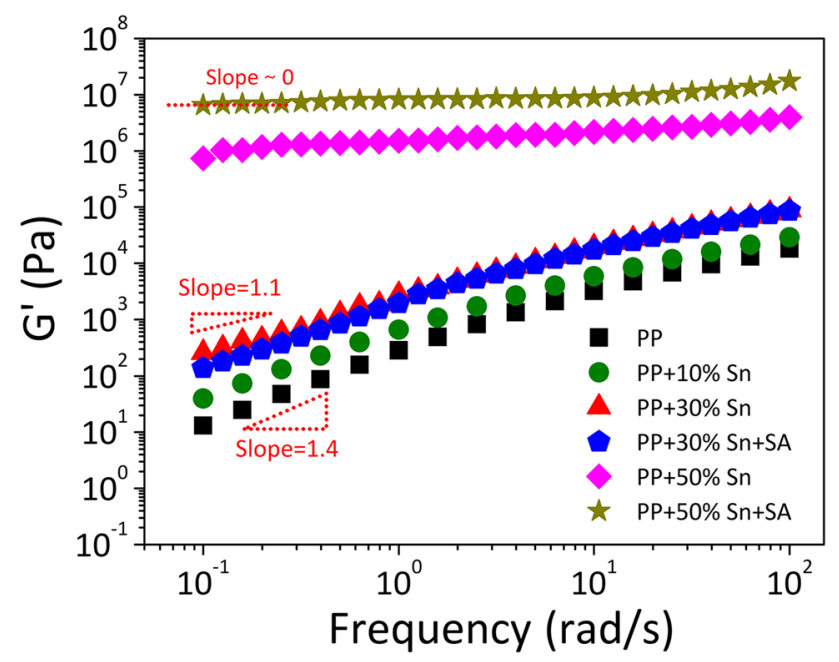

Fig. 3 Storage modulus as a function of angular frequency for all prepared composites at temperature of $190{ }^{\circ} \mathrm{C}$ thresholds. In other words, for the investigated systems, it was reasonable to hypothesize that the rheological percolation, i.e. the sol-gel transition, occurred first in the presence of the surfactant, between the 0.3 and 0.5 of solid fraction.

To gain a better understanding of findings, cyclical sequential testing (frequency, time, frequency, and strain sweep) at $190{ }^{\circ} \mathrm{C}$ on samples containing 30 vol. $\%$ Tin particles, with or without SA, has been conducted. Figure 4 depicts the experimental results.

Frequency sweep test displayed that both storage and loss modulus of two investigated materials remained comparable and behavior was mainly dominated by viscous contribution (see Fig. 4(a)). However, in the low frequency region, for $\mathrm{PP}+30 \%$ Sn systems, the G' was slightly superior compared to that recorded for $\mathrm{PP}+30 \% \mathrm{Sn}+\mathrm{SA}$.

The same samples were then subjected to time sweep experiments at low frequencies $(0.4 \mathrm{rad} / \mathrm{s})$ for a period of 5500 s (see Fig. 4(b).

Initially, storage modulus was lower than loss modulus in both samples, particularly in the low frequency region. As time passed, G' increased with a steeper slope than G", causing to converge with it at a characteristic point known as the crossover $\left(G^{\prime}=G^{\prime \prime}\right)$. The viscoelastic response of systems was dominated by filler/filler, filler/polymer, and polymer/ polymer interactions. However, the increase in storage modulus was mainly attributed to particle-particle interactions (Rueda et al. 2016). Due to contact forces between adjacent particles, an elastically deformable filler network was achieved (Handge et al. 2016). The trend of two moduli was interpreted as a sign of the percolation process, in which particles were structured to realize network pathways within the melted matrix. The percolation point was reached in samples containing stearic acid $(\mathrm{PP}+30 \% \mathrm{Sn}+\mathrm{SA})$ or without $(\mathrm{PP}+30 \% \mathrm{Sn})$ in 3700 and $5100 \mathrm{~s}$, respectively. This result was intended as a higher propensity in building particles network in the presence of additive.

Significant changes in $\mathrm{G}^{\prime}$ and $\mathrm{G}^{\prime \prime}$ curves were observed following frequency tests, as shown by comparing Fig. 4(a) and (c) for both specimens. However, when percolation occurred as expected, the rheological behaviour of both materials was drastically altered. In the case of SA addition, samples had a higher storage modulus ( $\left.G^{\prime}\right)$ than those of Tin and PP alone. As a result, once rheological percolation was achieved, the three-dimensional filler network of $\mathrm{PP}+\mathrm{Sn}+\mathrm{SA}$ was characterized by stronger interactions than systems without surfactant.

Finally, a comparison of storage modulus vs amplitude range at beginning and ending of cycle testing was shown in Fig. 4(d). Analogous values of the two curves, corresponding to $\mathrm{PP}+30 \% \mathrm{Sn}$ and $\mathrm{PP}+30 \% \mathrm{Sn}+\mathrm{SA}$ samples, were clearly detected once more. The modulus of both specimens after cycle testing was higher than that measured at the outset of the experiment. Furthermore, the $\mathrm{G}^{\prime}$ curve of 
Fig. 4 Cycle test at a temperature of $190{ }^{\circ} \mathrm{C}$ performed on samples at 30 vol.\% of particles content with and without SA:

(a) frequency sweep; (b) time sweep for a duration of $5500 \mathrm{~s}$ at $0.4 \mathrm{rad} / \mathrm{s}$ and strain 0.5 ; (c) frequency sweep; (d) strain sweep at $10 \mathrm{rad} / \mathrm{s}$ at the beginning test
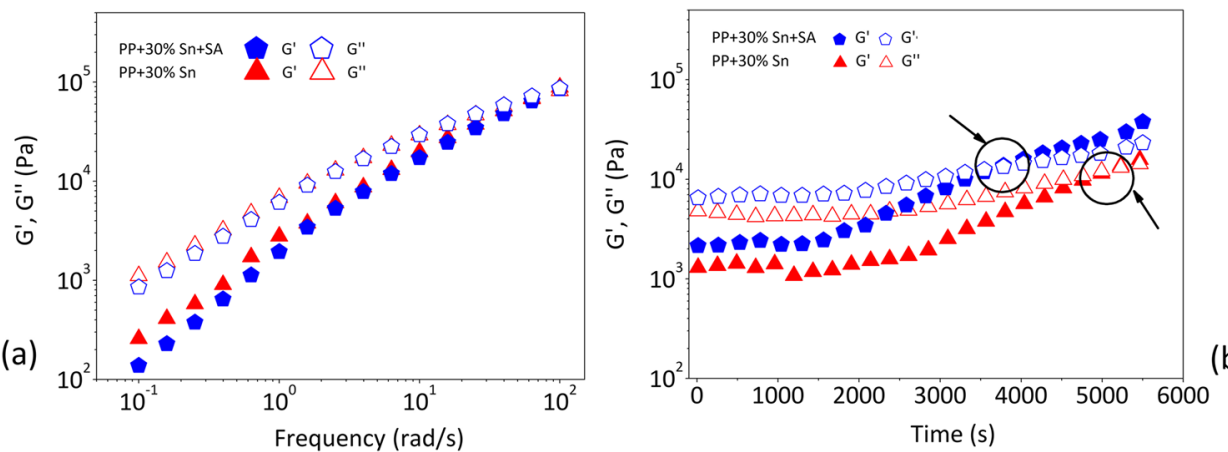

(b)

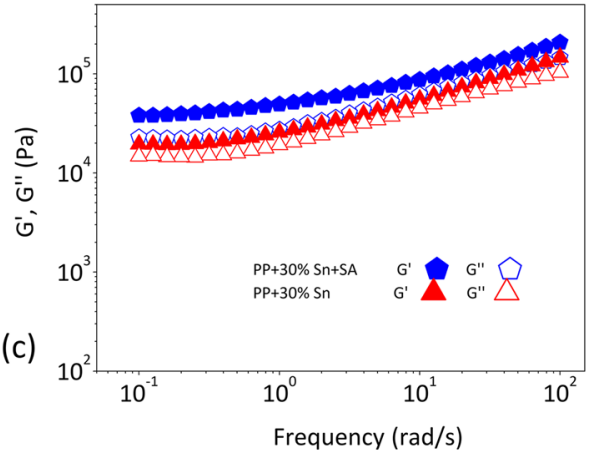

(d)
$\mathrm{PP}+30 \%$ Sn composites was marginally higher at the start of the test cycle than that of the systems at same filler loading containing the dispersant $(\mathrm{PP}+30 \% \mathrm{Sn}+\mathrm{SA})$. At the end of the cyclic test, after both materials had attained percolation, a completely opposite condition was confirmed. Even though the $G^{\prime}$ values were always quite close, the curve corresponding to materials containing the dispensing agent was slightly higher than that of systems without SA.

In summary, at the beginning of the cycle (frequency sweep), the elastic component for formulations at 30 vol.\% in filler loading was marginally higher compared to composites with the same proportion of filler content and including SA. The scenario was then reversed when the creation of percolated structures was induced, and the storage modulus of systems including the SA exceeded that of systems without the SA.

Figure 5 shows a schematic representation of the change in sample morphology during the time sweep tests. The morphology of both samples appeared to be very similar at first. The presence of SA was then found to increase the propensity of particles in 3D structuration over time.

During this phase, optical microscopy analysis was performed on both samples over time at low shear rate
Fig. 5 Schematic representation of building up of percolated filler network during time sweep for PP $+30 \% \mathrm{Sn}$ and $\mathrm{PP}+30 \% \mathrm{Sn}+\mathrm{SA}$

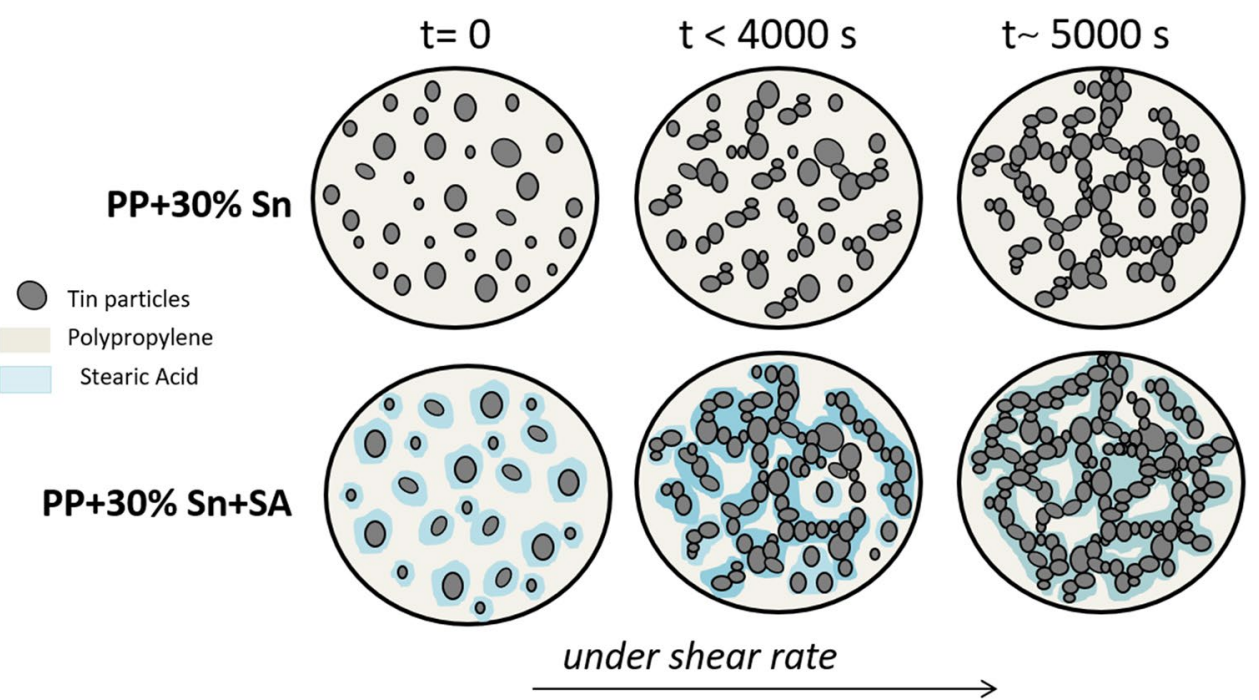


conditions to examine filler arrangement up to develop percolated filler structures, as shown in Fig. 6.

Figures 6(a) and (b) displayed the initial state of the sample's morphology (composites at $30 \mathrm{vol} \% \%$ of Tin particles, with SA or not) at $190{ }^{\circ} \mathrm{C}$ prior to the application of the shear rate. During the time, particles in solid state, within the organic melts, built up 3D interconnected structures under the influence of low shear rates $\left(0.1 \mathrm{~s}^{-1}\right)$ and temperature of $190{ }^{\circ} \mathrm{C}$ (i.e. below the melting point of Tin) (Fig. 6(c) and (d)).

\section{Rheological testing on melted particles in melted polymer-based compounds}

A further rheological characterization on composites at 30 vol.\% of Tin powder was conducted from $220{ }^{\circ} \mathrm{C}$ to $245^{\circ} \mathrm{C}$ while the particles fused (Jiang et al. 2006). Results of cycle testing are presented in Fig. 7.

In time sweep test at temperatures ranging from 220 to $245^{\circ} \mathrm{C}$, the storage and loss modulus changes in time were monitored for both samples.

Initially, for a constant temperature of $220^{\circ} \mathrm{C}$, the data of two prepared systems were very close to each other (see Fig. 7(a)). By increasing the time to $500 \mathrm{~s}$ while maintaining $220^{\circ} \mathrm{C}$, both moduli tended to increase, with only minor differences between the two samples. In particular, the $\mathrm{G}^{\prime}$ and $\mathrm{G}$ " values for $\mathrm{PP}+30 \% \mathrm{Sn}+\mathrm{SA}$ composites remained higher than those for PP $+30 \%$ Sn. In general, the G' near $10^{4} \mathrm{~Pa}$ was approximately two times lower than the value of G', by confirming liquid-like behavior for composites at temperature of $220^{\circ} \mathrm{C}$.
Then, for both systems, heating to $245^{\circ} \mathrm{C}$, which corresponded to particle fusion, resulted in a drastic reduction of storage and loss moduli. In particular, the collapse endured by the moduli in systems containing the surface modifier $(\mathrm{PP}+30 \% \mathrm{Sn}+\mathrm{SA})$ was greater than that observed in $\mathrm{PP}+30 \% \mathrm{Sn}$. When the time was increased to $2500 \mathrm{~s}$, the viscoelastic response of both composites remained timeindependent, with loss modulus superior to storage modulus.

A comparison of storage and loss moduli between the two systems at 30 vol.\% in filler loading with and without SA was reported following frequency sweep test at $245^{\circ} \mathrm{C}$ (Fig. 7(b)). According to the data, the G' and G" curves for samples with SA were lower than those for systems without SA. At this point the test temperature was reduced from $245{ }^{\circ} \mathrm{C}$ to $190{ }^{\circ} \mathrm{C}$, and the viscoelastic response of two materials was measured over time (Fig. 7(c)). Both moduli increased during the cooling, which lasted less than $250 \mathrm{~s}$, and then remained time-independent for the duration of the test. At 30 vol.\% filler content, samples without SA outperformed samples containing the fatty species in both moduli.

In the final step (see Fig. 7(d)), frequency tests were performed on the same systems at $190^{\circ} \mathrm{C}$. By comparing data collected at the beginning and end of the developed cycle, in the high frequency region, a correspondence of $\mathrm{G}^{\prime}$ curves was recorded for both $\mathrm{PP}+30 \% \mathrm{Sn}$ and $\mathrm{PP}+30 \% \mathrm{Sn}+\mathrm{SA}$ specimens. Once again, small differences in rheological parameters could be identified between the two investigated materials, and the response of $\mathrm{PP}+30 \% \mathrm{Sn}$ was confirmed to be greater than $\mathrm{PP}+30 \% \mathrm{Sn}+\mathrm{SA}$.

Then, for the same systems, the evolution of morphology was monitored as a function of temperature changes
Fig. 6 Micrographs at $190{ }^{\circ} \mathrm{C}$ : (a) and (c) PP $+30 \% \mathrm{Sn}$, and (b) and (d) $\mathrm{PP}+30 \% \mathrm{Sn}+\mathrm{SA}$, at zero time $(\mathrm{t}=0)$ and in progress $(t>0)$ with shear rates of $0.1 \mathrm{~s}^{-1}$, respectively (a)
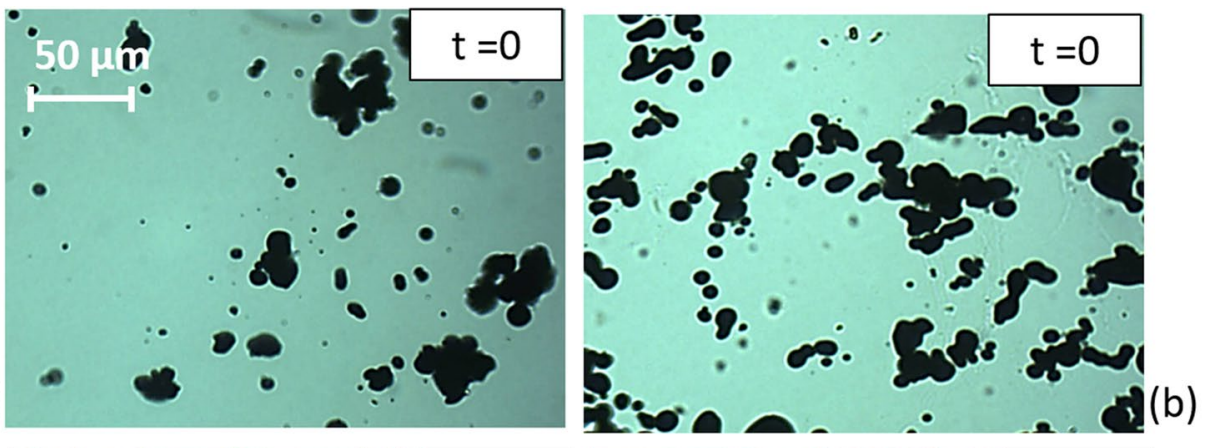

(c)

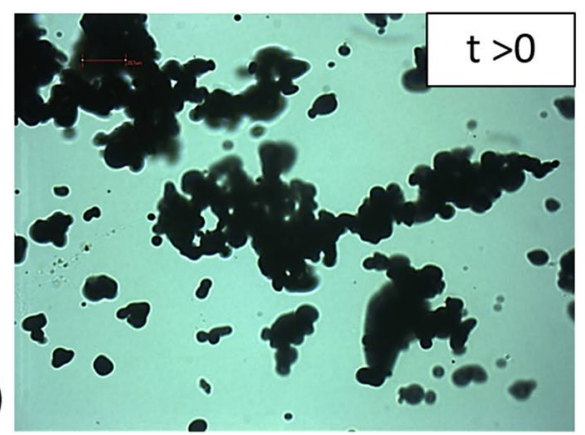

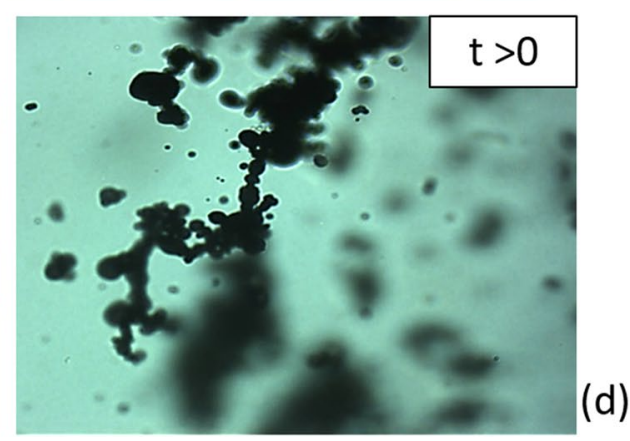


Fig. 7 Cycle test performed on samples at $30 \mathrm{vol} \%$ of particles content with and without SA: (a) time sweep at $220{ }^{\circ} \mathrm{C}$ for $600 \mathrm{~s}$, ramp of $20^{\circ} \mathrm{C} / \mathrm{min}$ up to $245^{\circ} \mathrm{C}$, and time sweep at $245^{\circ} \mathrm{C}$. In this step, the fixed frequency was $3.98 \mathrm{rad} / \mathrm{s}$ and strain was $1 \%$; (b) frequency sweep at strain of $1 \%$ and temperature of $245^{\circ} \mathrm{C}$; (c) ramp until $190{ }^{\circ} \mathrm{C}$ at $20^{\circ} \mathrm{C} /$ min, and time sweep for $600 \mathrm{~s}$ at $3.98 \mathrm{rad} / \mathrm{s}$ and $1 \%$; (d) comparison between storage moduli in frequency sweep test at $190{ }^{\circ} \mathrm{C}$ and strain of $1 \%$ at the beginning and ending of cycle
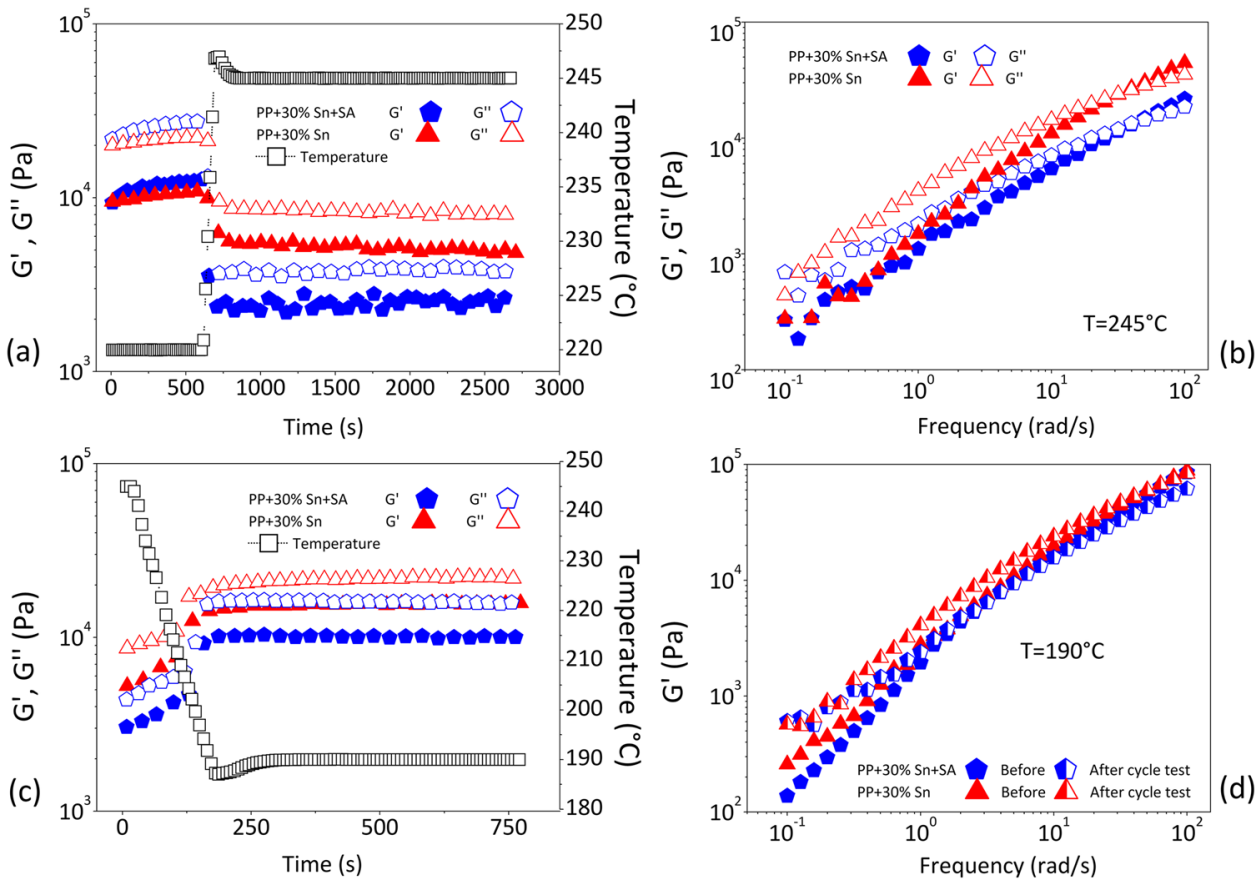

under the action of low shear rates $\left(0.1 \mathrm{~s}^{-1}\right)$. From $210^{\circ} \mathrm{C}$ up to $250{ }^{\circ} \mathrm{C}$, and then to $190{ }^{\circ} \mathrm{C}$, the solid/liquid transition, crossing the melting point of metal microparticles, was observed for PP $+30 \% \mathrm{Sn}$ and $\mathrm{PP}+30 \% \mathrm{Sn}+\mathrm{SA}$ samples. The microscopic investigations are reported in Fig. 8.

At $210{ }^{\circ} \mathrm{C}$, the particles appeared as dispersed drops in the molten $\mathrm{PP}$ with a board micrometric distribution ranging from 1 to $10 \mu \mathrm{m}$ for both compounds (Fig. 8(a) and (b)). In some areas, aggregates of the order of magnitude of $50 \mu \mathrm{m}$ may be visible. The shape of the particle could be described as pseudo-spherical or slightly ellipsoidal.

By increasing the temperature to $230{ }^{\circ} \mathrm{C}$ (Fig. 8(c) and (d)), and then to $250{ }^{\circ} \mathrm{C}$ (Fig. 8(e) and (f)), in addition to breakup and mass transfer, coalescence was found to be a determinant phenomenon affecting the evolution of drops and their size in multiphase flows. Indeed, as the temperature was raised, the edges of adjacent particles began to melt by retraining a small amount of liquid between them.

The drops remained in contact until the thickness of the film reached a critical value. At this point, the film was broken, and the coalescence had occurred (Lecocq et al. $2021 \mathrm{a}, \mathrm{b})$. At $250{ }^{\circ} \mathrm{C}$, liquid metal-polymer composites appeared to be made up of perfect spherical drops of melted metal particles dispersed within the melted polymer.

When mixing immiscible liquids, the minor component is usually present as dispersed phase (drops or filaments) in continuous phase of the major component. The deformation of dispersed drops in a flow field is a fundamental step in the mixing process. Drop deformation is then primarily governed by the capillary number $(\mathrm{Ca})$, which is the ratio of the external deforming flow field's shear stress $(\tau)$ to the drop's interfacial stress conserving the shape $\left(\frac{\sigma}{R}\right)$ :

$C_{a}=\frac{\tau R}{\sigma}=\frac{\eta_{c} \dot{\gamma} R}{\sigma}$

where $\eta_{c}$ is the viscosity of the continuous phase and the $\dot{\gamma}$ shear rate. Above a critical value $\left(\mathrm{Ca}_{\text {crit }}\right)$, viscous shear stress prevails over interfacial stress and there is no stable drop form of equilibrium. The drop gets longer and eventually breaks into fragments. Successive researches have revealed that the critical capillary number is affected by both the flow type and the viscosity ratio (p) between dispersed and continuous phase. When $\mathrm{p}=1$ under quasi-equilibrium conditions, it is easier to deform and break drops (Janssen and Meijer 1995).

In our study, given the high interfacial tension of $140 \pm 20 \mathrm{mN} / \mathrm{m}$ between the PP and melted Tin (Lecocq et al. $2021 \mathrm{a}, \mathrm{b})$, the pseudo-spherical shape was thought to be the only practical attainable morphology. Furthermore, there was no evidence of particle deformation during shear flow. This feature was caused by weak shear rate that was insufficient to promote the elongation of the drop in the flow direction. The motion of particles in a sheared suspension was well described in work of Rumscheidt and Mason (1961) by correlating the deformation and breakup of fluid drops to the viscosity ratio of the two phases. The effect of adding an emulsifier was also explained in hyperbolic or shear flow conditions, as well as at rest. It was demonstrated, in particular, that the additive formed an interfacial film on the particle surface, 
Fig. 8 Optical microscopic images of $\mathrm{PP}+30 \% \mathrm{Sn}$ under low shear rate $\left(0.1 \mathrm{~s}^{-1}\right)$ and changes in temperatures: starting from $210{ }^{\circ} \mathrm{C}$ (a), going through $230^{\circ} \mathrm{C}(\mathbf{c})$, and $250{ }^{\circ} \mathrm{C}(\mathbf{e})$, up to $190{ }^{\circ} \mathrm{C}$ (g). Analogously, the same observations were conducted on $\mathrm{PP}+30 \% \mathrm{Sn}+\mathrm{SA}$ at $210{ }^{\circ} \mathrm{C}(\mathbf{b})$, going through $230{ }^{\circ} \mathrm{C}(\mathbf{d})$, and $250{ }^{\circ} \mathrm{C}$ (f), up to $190{ }^{\circ} \mathrm{C}(\mathbf{h})$. A magnification of $50 \mu \mathrm{m}$ was chosen for all the images (a)
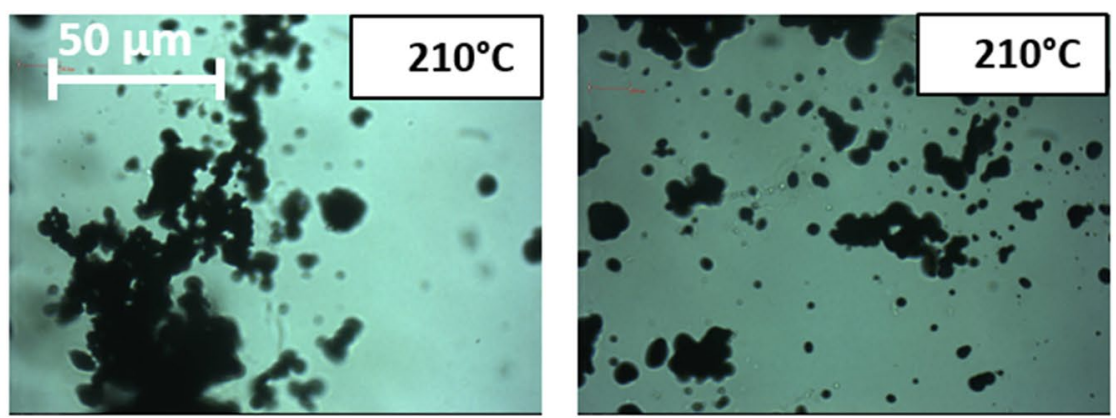

(b)

(c)
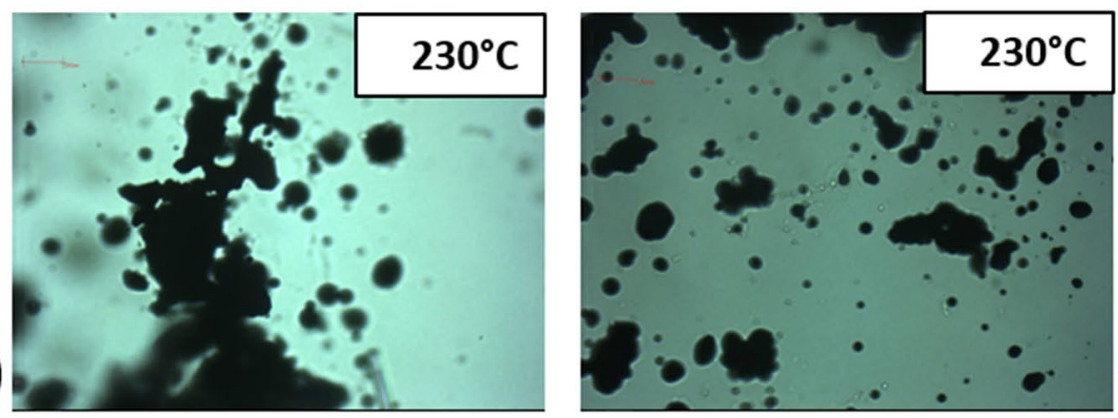

(d)

(e)
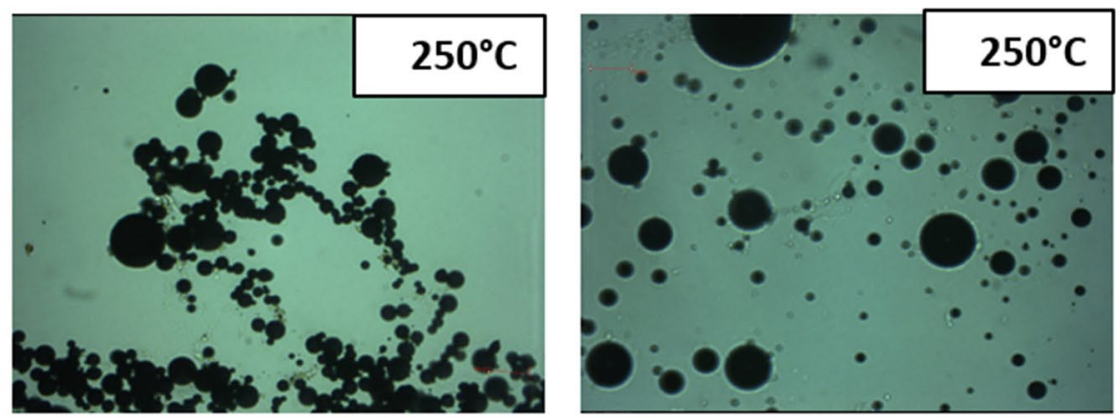

(f)

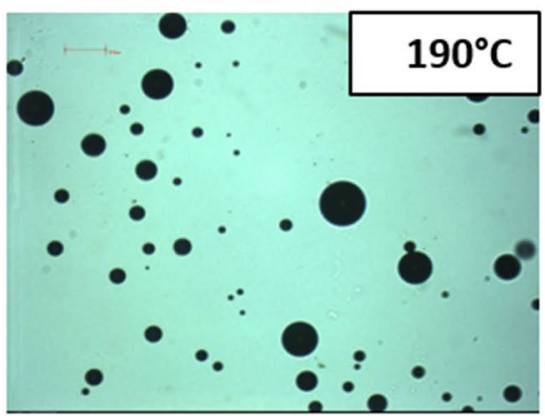

(h) which hampered shear stress transmission by forming a pressure gradient. However, no changes in the class of deformation have been observed in shear flow after the addition of an emulsifier.

When the temperature of the two systems was reduced from $250{ }^{\circ} \mathrm{C}$ to $190{ }^{\circ} \mathrm{C}$ (Fig. $8(\mathrm{~g})$ and (h)), the particles returned to solid phase, but the pseudo-spherical aspect remained, and no difference could be highlighted during the cooling.

\section{Discussion}

Good dispersion and high compatibility between two phases (filler/matrix) are required to achieve the desired properties in a composite. Because of the tendency of the particles to agglomerate, these prerogatives become even more critical as the filler loadings within the resin increase. The van der Waals, double layer (electrostatic), 
and steric (polymeric) forces dominate interparticle forces in HF suspensions (Sigmund et al. 2000). The most common method for stabilizing a suspension is to increase the last two forces, either by forming an electrostatic double layer at the solid-liquid interface or by adsorbing polymers or surfactants on the particle surface (Rueda et al. 2017a).

In this work, polypropylene, a non-polar matrix, was combined with polar Tin particles. Because of its potential role as a compatibilizing and dispersing agent, stearic acid was added in PP/Tin formulations to improve the properties of final compositions. The morphological aspects of composites with or without fatty acid were investigated both directly and indirectly using microscopic analysis and rotational rheology also by changing the testing temperature. At $190{ }^{\circ} \mathrm{C}$, when comparing systems with 30 vol.\% Tin particles, whether containing SA or not, only minor differences between samples were verified, with the G' curve of $\mathrm{PP}+30 \%$ Sn systems slightly higher than of $\mathrm{PP}+30 \% \mathrm{Sn}+\mathrm{SA}$ systems. Following cyclic tests on these samples, it was discovered that the presence of stearic acid accelerated the formation of percolated structures causing the modulus of the PP $+30 \% \mathrm{Sn}+\mathrm{SA}$ samples to be higher than that of the $\mathrm{PP}+30 \% \mathrm{Sn}$ samples. This observation was then confirmed by examining the G' curves of the samples at $50 \mathrm{vol} . \%$ particle content with and without acid. In fact, in this case, the elastic component ( $\left.\mathrm{G}^{\prime}\right)$ of samples containing SA exceeded that of systems without dispersant at the same filler content. This was interpreted as indicating that the former systems achieved higher filler/filler and filler/ matrix interactions than the latter.

The final outcome was in contrast with the analysis conducted by Wan et al. (2020), on the effect of surface functionalization on interfacial compatibility and interactions of polymer/particle systems. Here, the authors proposed three levels of filler dispersion based on filler functionalization and matrix nature. In systems without chemical modification, serious filler aggregation and strong interfacial interactions were developed, resulting in deterioration of thermo-mechanical properties. Less aggregation and strong interfacial interaction were observed when particles were modified with polar groups. Finally, a uniform particle distribution was verified in the case of a-polar surface modifier.

The universal usefulness of stearic acid as surface modifier in the polymer formulations and composite processing was fully illustrated in a recent review by Patti et al. (2021). The authors gathered the countless literature studies that have implied, in each investigated formulation, the incorporation of SA as an additive, which was very useful for a variety of purposes and had a plethora of industrial applications. Two sections were dedicated to describing the surface modification induced by SA on the different types of involved surfaces and the effect of SA on the rheological properties of polymer-based systems.
The mechanism of fatty acid absorption on particles surface has been subject of scientific debate. There are two possible mechanisms to consider (Buckley 1981): the first is physisorption, which occurs when binding interactions are less than $40 \mathrm{~kJ} / \mathrm{mol}$. This mechanism does not require any specific chemical functions because it is based on intermolecular forces such as van der Waals or hydrogen bonds. When binding interactions exceed $40 \mathrm{~kJ} / \mathrm{mol}$, the absorption mechanism is referred as chemisorption. Stearic acid's reaction on mineral and metall surfaces has previously been reported by Zürcher and Graule (2005), with a chemical equation proposing an exchange of acid $\mathrm{H}+$ of the stearic acid and formation of a covalent bond with metal atoms. After that, a more detailed mechanism was described by Lim et al. (2007) proposing monodentate, bidentate or bringing bond. The first was realized by the interaction of one oxygen of the fatty acid carboxyl group and one metal atom (monodentate), the second by the interaction of the two oxygens and one metal atom (bidentate), and the last by the interaction of the two oxygens with two different metal atoms (bringing). As a result of mixing the liquid stearic acid and Tin metal fillers with the molten PP matrix, a covalently bonded layer of stearic acid could be imagined on the filler metallic surfaces (Lecocq et al. 2021a, b).

Also the mechanism of interaction between stearic acid and polypropylene is unclear. The aliphatic tail of stearic acid was thought to be too short to entangle with polypropylene molecules. In general, the modifier molecules should be sufficiently long and compatible with the matrix to ensure strong physical bonding (Pukanszky et al. 1989).

Stearic acid treatment had significant effects on the physical and chemical properties of treated surfaces, as well as on the rheology of mixtures or composites containing the treated filler. In particular, it was reported that the stearic acid lowered yield stress of composites at high filler content, which was consistent with most studies in the literature (Tseng et al. 1999; Tseng and Teng 2001) implying that, in this range of filler concentrations, the decrease of particle network strength predominated over other contributions, such as the increase of particle bonds, which was dominant in the low concentration range. A significant reduction in shear viscosity during extrusion was observed in composites filled with SA-modified calcium carbonate $\left(\mathrm{CaCO}_{3}\right)$ when compared to composites based on unmodified fillers (Dangtungee et al. 2005). The processing of polyethylene containing $\mathrm{CaCO}_{3}$ fillers treated with stearic acid revealed much wider flow regimes free of surface distortions caused by increased wall slip (Barczewski et al. 2017).

In terms of power law dependence, it was found that the value of the exponent $\mathrm{m}$ decreased from 3.6 in compositions without stearic acid to 2.1 in formulations containing the stearic acid which indicated the contribution of SA in lowering the inter-particle interactions (Auscher et al. 2017). 
Data on rheology of polyethylene filled with spherical zirconia $(\mathrm{d}=0.2 \mu \mathrm{m})$ over a broad span of particle concentrations (0 to 42 vol.\%) by Auscher et al. (2017) fully confirmed that the presence of stearic acid reduced the interfacial forces, improved filler/matrix compatibility, and resulted in lower percolation thresholds. A comparison of samples with or without SA, and equal filler content, highlighted lower values of storage modulus and yield stress in situations where the fatty acid was added. Beyond the percolation threshold in the domain of highly filled polymers, a decrease in particle network strength in the presence of stearic acid was observed. Stearic acid was thought to help to reduce the attractive interactions between particles in the concentration domain between the rheological percolation threshold and the maximum packing fraction. Here, it was concluded that the presence of SA promoted breakage of agglomerates by leading to uniform particles distribution. When molecular chains were absorbed on the particle surface, the steric forces promoted particles repulsion by preventing the agglomeration. In this way, attractive interactions between particles, i.e. London-van der Waals forces - which occur when particles are close enough - were lowered by determining weak and brittle three-dimensional networks. During mixing, the agglomerates of the two systems, whether stearic acid-containing or not, might be subject to breakage or erosion phenomena, becoming smaller units with a high aspect ratio. However, since the energy barrier required to break down agglomerates was expected to be lower in stearic acidcontaining compounds, in the latter case, more aggregates with high aspect ratios should have been produced at the end of the mixing process. These considerations were confirmed by SEM images by attesting the presence of smaller aggregates with higher aspect ratio in compounds containing the fatty species. Then, the authors evaluated the thickness of SA layer (e) around particles by the following equation (Eq. (2))

$e=\frac{C_{S A}}{S S A \times \rho_{S A}}$

where $C_{S A}$ is the weight concentration of adsorbed SA relative to the powder surface, SSA represents the specific surface area of the powder, and $\rho_{S A}$ is the SA density (fixed equal to $0.94 \mathrm{~g} / \mathrm{cm}^{3}$ ). By the formula, it was found that, for $2.5 \mathrm{wt} . \%$ of SA content, the thickness was equal to $1.7 \mathrm{~nm}$. Then, by considering single carbon-carbon binding of $0.09 \mathrm{~nm}$ in length, it was concluded that $2.5 \mathrm{wt} . \%$ of SA could correspond roughly to a monolayer around particles.

Similarly, Lecocq et al. (2021a, b) calculated that the SA concentration for creating a monolayer around particles in systems made of PP and Tin powder $(\mathrm{d}=45 \mu \mathrm{m})$ was $0.0037 \mathrm{wt} . \%$. The purpose of this study was to investigate the electromagnetic interference shielding of PP filled with stearic acid and metal filler. The final data demonstrated an improvement in shielding performance due to changes in material morphology caused by surface modification of Tin particles in the presence of SA. When SA was introduced into compounds, microscopic analysis revealed an increase in particle aggregation. The authors proposed a three-step mechanism for illustrating the influence of SA on sample morphology during compounding. Initially, the constituents, namely molten SA and solid particles, were evenly distributed within the molten PP; however, during mixing, the SA interacted with the particles and exerted an attractive force on them, resulting in aggregation (Paper under revision).

The knowledge of different values of adsorbed SA content to realize a monolayer surrounding the particles, depending on powder type, i.e. $2.5 \mathrm{wt}$ \% for zirconia (Auscher et al. 2017) and $0.0037 \mathrm{wt} . \%$ for Tin powder (Lecocq et al. 2021a, b), allowed to explain the contrasting effect induced by SA on the rheological behavior and morphological aspects of respective composites. In fact, while in zirconia-based compositions (Auscher et al. 2017) the adopted content of SA was just above the monolayer concentration, in Tin-based formulations (Lecocq et al. 2021a, b), the introduced SA amount was much over than the minimum required for covering the particle with a single layer. In these conditions, it could be imagined that without Tin particles, the SA would be segregated outside the matrix, by coming at the interface between polymer and metal surfaces of the processing machine. When, Tin particles were introduced in PP/SA systems, interactions between fatty acid and fillers took place. If more SA content was added than was required for the formation of an absorbed monolayer on the particles, but the volumetric fraction of filler in the polymer was less than the percolation threshold (case of $30 \mathrm{vol} . \%$ of Tin particles), the fatty species could still have the expected effect, which meant a reduction in storage modulus, albeit in a less significant way. When the filler concentrations in the polymer exceeded the percolation threshold (case of $50 \mathrm{vol} \% \%$ of Tin particles), the surplus of stearic acid remained blocked in the threedimensional structure. Being no longer able to migrate to the sample surface, SA caused filler aggregations and, as a result, an increase in modulus.

These were the alleged conditions in solid particle/melted polymer systems at $190{ }^{\circ} \mathrm{C}$. Then, once the melting temperature of the Tin materials was overcome (testing temperature $=245^{\circ} \mathrm{C}$ ), it was possible to hypothesize that during the fusion, as a result of the coalescence, the surface area of particles was reduced (Koch and Friedlander 1990) being the same filler fraction within the matrix. In this condition, the excess acid content, trapped in the filler network, was released by reaching the interface between composites and metal parts of the mixing apparatus. 


\section{Conclusion}

This study was focused on the rotational rheological measurements of highly filled Tin suspensions in polypropylene, with and without the addition of the stearic acid. By analyzing the flow nature of the developed samples at temperatures of $190{ }^{\circ} \mathrm{C}$, it was observed that the presence of SA in formulations reduced the range of linear behaviour, attained in correspondence of a lower strain compared to mixtures not containing the additive. Then, once exceeded the percolation threshold of particles within the matrix, the use of the SA in these composites determined superior storage and loss moduli values compared to the same formulations, realized without the additive. This was intended a sign of the greater propensity of fillers to create 3D percolated networks inside the matrix in the presence of the SA at testing temperatures of $190{ }^{\circ} \mathrm{C}$. Yet, the latter consideration was in contrast to the scientific literature involving the same field of interest, and to the rheological data collected at a temperature of $245^{\circ} \mathrm{C}$. In fact, in these conditions, the G' and G' curves of PP/Sn systems remained above that of $\mathrm{PP} / \mathrm{Sn} / \mathrm{SA}$ composites at an equal filler content. These results were supported by considering the introduced amount of additive in the formulations and the minimum SA content required to form a monolayer around the particles. In other words, the effect of stearic acid on the viscoelastic behavior of PP/Tin particles composites and sample morphology was found to be dependent on the amount of stearic acid and the fraction of filler used in the polymer-based formulations. If the SA content was much higher than that required to cover the particles with a monolayer, and the filler fraction was greater than the percolation threshold, the stearic acid could remain trapped in the three-dimensional network of the percolated structure, favoring interactions and particle agglomeration.

Acknowledgements A. Patti wishes to thank the Italian Ministry of Education, Universities and Research (MIUR) in the framework of Action 1.2 "Researcher Mobility" of the Axis I of PON R\&I 20142020. H. Lecocq would like to thank TOTAL and the Association Nationale Recherche Technologie (ANRT) for their financial support.

Funding Open access funding provided by Università degli Studi di Cataniawithin the CRUI-CARE Agreement.

Data and materials availability The data presented in this study are available on request from the corresponding author.

Code availability Not applicable.

\section{Declarations}

Conflict of interest The authors declare no competing interests.

Open Access This article is licensed under a Creative Commons Attribution 4.0 International License, which permits use, sharing, adaptation, distribution and reproduction in any medium or format, as long as you give appropriate credit to the original author(s) and the source, provide a link to the Creative Commons licence, and indicate if changes were made. The images or other third party material in this article are included in the article's Creative Commons licence, unless indicated otherwise in a credit line to the material. If material is not included in the article's Creative Commons licence and your intended use is not permitted by statutory regulation or exceeds the permitted use, you will need to obtain permission directly from the copyright holder. To view a copy of this licence, visit http://creativecommons. org/licenses/by/4.0/.

\section{References}

Achilleos EC, Georgiou G, Hatzikiriakos SG (2002) Role of processing aids in the extrusion of molten polymers. J Vinyl Addit Technol 8:7-24. https://doi.org/10.1002/vnl.10340

Auscher MC, Fulchiron R, Périé T, Cassagnau P (2017) Morphological and rheological properties of zirconia filled polyethylene. Polymer (guildf) 132:174-179. https://doi.org/10.1016/j.polym er.2017.10.068

Barczewski M, Lewandowski K, Schmidt M, Szostak M (2017) Melt fracture and rheology of linear low density polyethylene - calcium carbonate composites. Polym Eng Sci 57:998-1004. https://doi.org/10.1002/pen.24477

Buckley DH (1981) Surface effects in adhesion, friction, wear and lubrication. Elsevier, Amsterdam

Cao B, Zhou Y, Wu Y et al (2020) Simultaneous improvement of processability and toughness of highly filled MH/LLDPE composites by using fluorine-containing flow modifiers. Compos Part A Appl Sci Manuf 134:105900. https://doi.org/10.1016/j. compositesa.2020.105900

Cassagnau P (2003) Payne effect and shear elasticity of silica-filled polymers in concentrated solutions and in molten state. Polymer (guildf) 44:2455-2462. https://doi.org/10.1016/S0032-3861(03) 00094-6

Cassagnau P (2008) Melt rheology of organoclay and fumed silica nanocomposites. Polymer (guildf) 49:2183-2196

Cassagnau P, Mélis F (2003) Non-linear viscoelastic behaviour and modulus recovery in silica filled polymers. Polymer (guildf) 44:6607-6615. https://doi.org/10.1016/S0032-3861(03) 00689-X

Dangtungee R, Yun J, Supaphol P (2005) Melt rheology and extrudate swell of calcium carbonate nanoparticle-filled isotactic polypropylene. Polym Test 24:2-11. https://doi.org/10.1016/j. polymertesting.2004.08.006

Dasari A, Yu ZZ, Mai YW, Liu S (2007) Flame retardancy of highly filled polyamide 6/clay nanocomposites. Nanotechnology 18:445602. https://doi.org/10.1088/0957-4484/18/44/445602

Deshmukh K, Ahamed MB, Deshmukh RR et al (2016) Biopolymer Composites in Electronics, 1st edn. Elsevier Inc., Amsterdam

Drozdov AD, deClaville CJ (2019) Thermal conductivity of highly filled polymer nanocomposites. Compos Sci Technol 182:107717. https://doi.org/10.1016/j.compscitech.2019.107717

Fallon JJ, McKnight SH, Bortner MJ (2019) Highly loaded fiber filled polymers for material extrusion: a review of current understanding. Addit Manuf 30:100810

Gonzalez-Gutierrez J, Cano S, Schuschnigg S et al (2018) Additive manufacturing of metallic and ceramic components by the material extrusion of highly-filled polymers: a review and future perspectives. Materials (basel) 11:840. https://doi.org/10.3390/ ma11050840

Handge UA, Wolff MFH, Abetz V, Heinrich S (2016) Viscoelastic and dielectric properties of composites of poly(vinyl butyral) 
and alumina particles with a high filling degree. Polymer (guildf) 82:337-348. https://doi.org/10.1016/j.polymer.2015.11.047

Hussain ARJ, Alahyari AA, Eastman SA et al (2017) Review of polymers for heat exchanger applications: factors concerning thermal conductivity. Appl Therm Eng 113:1118-1127

Janssen JMH, Meijer HEH (1995) Dynamics of liquid-liquid mixing: a 2-zone model. Polym Eng Sci 35:1766-1780. https://doi.org/ $10.1002 /$ pen.760352206

Jiang H, Moon K, sik, Dong H, et al (2006) Size-dependent melting properties of tin nanoparticles. Chem Phys Lett 429:492-496. https://doi.org/10.1016/j.cplett.2006.08.027

Kajohnchaiyagual J, Jubsilp C, Dueramae I, Rimdusit S (2014) Thermal and mechanical properties enhancement obtained in highly filled alumina-polybenzoxazine composites. Polym Compos 35:2269-2279. https://doi.org/10.1002/pc.22892

Koch W, Friedlander SK (1990) The effect of particle coalescence on the surface area of a coagulating aerosol. J Colloid Interface Sci 140:419-427. https://doi.org/10.1016/0021-9797(90)90362-R

Lazzeri A, Zebarjad SM, Pracella M et al (2005) Filler toughening of plastics. Part 1 - the effect of surface interactions on physicomechanical properties and rheological behaviour of ultrafine CaCO3/HDPE nanocomposites. Polymer (guildf) 46:827-844. https://doi.org/10.1016/j.polymer.2004.11.111

Lecocq H, Lhost O, Serghei A, Cassagnau P (2021b) Droplet relaxation of molten metals in polypropylene matrix: measurement of the interfacial tension. J Rheol (n Y N y) 65:391-404. https://doi. org/10.1122/8.0000176

Lecocq H, Lhost O, Cassagnau P, Serghei A (2021) A super-high electromagnetic interference shielding of polypropylene-based composite materials filled with stearic acid treated hybrid metallic fillers. (Submitted)

Lim MS, Feng K, Chen X et al (2007) Adsorption and desorption of stearic acid self-assembled monolayers on aluminum oxide. Langmuir 23:2444-2452. https://doi.org/10.1021/la061914n

Moore AL, Shi L (2014) Emerging challenges and materials for thermal management of electronics. Mater Today 17:163-174

Nikzad M, Masood SH, Sbarski I (2011) Thermo-mechanical properties of a highly filled polymeric composites for Fused Deposition Modeling. Mater Des 32:3448-3456. https://doi.org/10.1016/j. matdes.2011.01.056

Palza H, Reznik B, Kappes M et al (2010) Characterization of melt flow instabilities in polyethylene/carbon nanotube composites. Polymer (guildf) 51:3753-3761. https://doi.org/10.1016/j.polym er.2010.06.016

Patti A, Lecocq H, Serghei A et al (2021) The universal usefulness of stearic acid as surface modifier: applications to the polymer formulations and composite processing. J Ind Eng Chem 96:1-33

Planes E, Gloaguen F, Albérola N, Flandin L (2013) Spatial distribution of the electrical conductivity in highly filled polymers: experiment, modeling, and application to bipolar plates. J Appl Phys 114:223710. https://doi.org/10.1063/1.4841155

Pukanszky B, Todos F, Jan J, Kolairi J (1989) The possible mechanisms of polymer-filler interaction in polypropylene- $\mathrm{CaCO}_{3} \mathrm{com}-$ posites. J Mater Sci Lett 8:1040-1042.

Renger C, Kuschel P, Kristoffersson A et al (2007) Rheology studies on highly filled nano-zirconia suspensions. J Eur Ceram Soc 27:2361-2367. https://doi.org/10.1016/j.jeurceramsoc.2006.08. 022

Rueda M, Fulchiron R, Cassagnau P et al (2016) Structuring of nonBrownian ferrite particles in molten polypropylene: Viscoelastic analysis. J Rheol (n Y N y) 60:1245-1255. https://doi.org/10. $1122 / 1.4963801$

Rueda MM, Auscher MC, Fulchiron R et al (2017a) Rheology and applications of highly filled polymers: A review of current understanding. Prog Polym Sci 66:22-53

Rueda MM, Fulchiron R, Martin G, Cassagnau P (2017b) Linear and non-linear nature of the flow of polypropylene filled with ferrite particles: from low to concentrated composites. Rheol Acta 56:635-648. https://doi.org/10.1007/s00397-017-1025-0

Rumscheidt FD, Mason SG (1961) Particle motions in sheared suspensions XII. Deformation and burst of fluid drops in shear and hyperbolic flow. J Colloid Sci 16:238-261. https://doi.org/10. 1016/0095-8522(61)90003-4

Sigmund WM, Bell NS, Bergström L (2000) Novel powder-processing methods for advanced ceramics. J Am Ceram Soc 83:1557-1574. https://doi.org/10.1111/j.1151-2916.2000.tb01432.x

Tseng WJ, Teng KH (2001) Effect of surfactant adsorption on aggregate structure and yield strength of zirconia-wax suspensions. J Mater Sci 36:173-178. https://doi.org/10.1023/A:1004805523977

Tseng WJ, Liu DM, Hsu CK (1999) Influence of stearic acid on suspension structure and green microstructure of injection-molded zirconia ceramics. Ceram Int 25:191-195. https://doi.org/10.1016/ S0272-8842(98)00024-8

Wan YJ, Li G, Yao YM et al (2020) Recent advances in polymer-based electronic packaging materials. Compos Commun 19:154-167

Zhu S, Zhang Y, Zhang Y (2002) Effects of silicone oil and polymeric modifiers on the mechanical properties of highly filled LLDPE. J Appl Polym Sci 83:121-128. https://doi.org/10.1002/app.2234

Zürcher S, Graule T (2005) Influence of dispersant structure on the rheological properties of highly-concentrated zirconia dispersions. J Eur Ceram Soc 25:863-873. https://doi.org/10.1016/j.jeurcerams oc.2004.05.002

Publisher's note Springer Nature remains neutral with regard to jurisdictional claims in published maps and institutional affiliations. 